\title{
Tampering of Gender Issues in the Translation of Umrao Jan Ada translated as The Courtesan of Lucknow
}

\author{
AHMAD YAR KHAN (CORRESPOPNDING AUTHOR) \\ School of Languages, Literacies and Translation \\ Universiti Sains Malaysia \\ aykhan81@yahoo.com \\ MALINI GANAPATHY \\ School of Languages, Literacies and Translation \\ Universiti Sains Malaysia \\ malinik@usm.my \\ BITA NAGHMEH ABBASPOUR \\ School of Languages, Literacies and Translation \\ Universiti Sains Malaysia \\ bitana@usm.my
}

\begin{abstract}
The present study investigates the lexical choices of the translators in terms of gender issues discussed in the novel The Courtesan of Lucknow (Umrao Jan Ada) translated by Khushwant Singh and M. A. Husaini. The study aims to analyze the ideologically loaded lexis (related to gender issues) of the novel with its translation. The aim is to further examine and find out how the lexical choices of the translators manipulate the original idea of the writer. The study employs Critical Discourse Analysis (CDA) as its theoretical and analytical framework for ideological manipulation of gender issues. The findings reveal that the use of different lexical choices of the translators has changed the ideological stance of the writer. This study will contribute both to the discipline of translation studies and literary translation. The novel has been studied from the perspective of feminist and literary aesthetics but the comparative aspect of both texts from a gender perspective is lacking. Therefore, the current study is an attempt to examine the ideological manipulation of gender issues of both source and target texts at the lexical level. The findings reveal that the translators have misrepresented the gender issues.
\end{abstract}

Key Words: Manipulation, Ideology, CDA, Feminism, Gender Issues, Umrao Jan Ada

Published online: October 2021

To cite this article: Khan, A. Y., \& Ganapathy, M. \& Abbaspour, B. N. (2021). Tampering of Gender Issues in the Translation of Umrao Jan Ada translated as The Courtesan of Lucknow. International Journal of Language, Literacy and Translation 4(2), 30-47. https://doi.org/10.36777/ijollt2021.4.2.046

To link to this article: https://doi.org/10.36777/ijollt2021.4.2.046

This work is licensed under the terms of the Creative Commons Attribution (CC BY) (https://creativecommons.org/licenses/by/4.0/). 


\section{INTRODUCTION}

Gentzler and Tymoczko (2002) are of the view that translation is a complex phenomenon of time, place, conflict, historical and material moments, and specific situations of translation, as well as socio-cultural and ideological factors, determined the ways of translators (Sanatifar, 2013). Consequently, translation cannot be considered as a faithful and transparent activity but rather a conscious act of selection, assemblage, structuration, and fabrication. Often the translation takes the form of falsification, refusal of information, counterfeiting, and secret codes creation (cited in Aklalouch, 2020). This aspect of translation exhibits the creative aspect of writing. Translation is thus not a neutral activity whereby it involves shaping reality in different ways.

Translation is both a linguistic and a cultural phenomenon. They cannot be separated from each other. Language is embedded in culture, the meaning of the linguistic item can be understood only with its cultural context surrounding it (House, 2018). Translation is a process in which the translators make decisions to select from a wide variety of lexical and grammatical choices (Mansourabadi \& Karimnia, 2013). Hatim and Mason (2005) are of the view that the choice of translators depends on their ideological orientation. Thus, among many factors like patronage, poetics, discursive practices, ideology is one of the most important factors that can influence the choice of the translators. The influence and lexical choice of translators can take the form of manipulation (Mansourabadi \& Karimnia, 2013). The manipulation aspect of translation is propounded by Lefevere (1992) (Sharififar et al., 2016) while the ideological manipulation of gender issues as a translation issue is offered by Von Flotow (1997) (Hatim \& Mason, 2005).

This study will take into account the gender issues that have been manipulated in the translation of an Urdu novel Umrao Jan Ada. The novel is translated into English as The Courtesan of Lucknow by K. Singh and M.A Hussaini. The study will also take into account the Farahzad's (2012) translation criticism model of CDA in order to unearth the concealed ideology of the translators.

The writer has presented the status of women folks as a group through the character of Umrao Jan Ada. The role of women in the Indian society has been shown as subordinate to men. They are considered as an object of sexual objectification, gratification, and household management, and are excluded from access to political, social and economic resources.

In addition, the writer has presented a feminist stance of the life of Umrao Jan Ada and the cultural hindrances as well as sexual exploitation of women folks in the Indian subcontinent. Umrao Jan Ada is a type character and represented the women folk in the novel and their exploitation in the patriarchal setup. Contrary to the ideology of the writer, both the translators on the other hand have presented a gendered and sexist ideology different from the writer of the ST. The writer as well as the novel is a manifestation of feminism but the translators have proved to the representative of the patriarchal mindset instead of feminism. Because the translators have damaged and manipulated the feminist stance of the writer by manipulating the gender issues of the ST in their translation of the ST.

Somech and Zahavi (2016) are of the view that the study of gender issues deserve consideration for it has been a mechanism for gendered behavior, preferences and decisions throughout the family and at job (OECD, 2015; Somech \& Zahavy, 2016).

The prior studies concede to the fact that gendered role ideology is a function of interest-based accounts. (Bolzendahl and Myers 2004). The patraichal ideology believes in a traditional gender beliefs because the men may gain more from women's unequal division of family and domestics 
tasks (Somech \& Zahavy, 2016). Thus, the patraichal setup will always try to avoid to lose the power and resources from an egalitarian environment. Such phenomenon can only be changed when the people are made aware of an egalitarian environment about gender issues by highlighting and eliminating of those cultural and religious values which prove to be a hindrance in the elimination of gendered ideology. The study of the principles of manipulation of gender issues in the translation of an Urdu novel Umrao Jan Ada (The Courtesan of Lucknow) is necessary in order to highlight those gender issues that have been manipulated in the target text.

\section{LITERATURE REVIEW}

The feminist used descriptively the concept of gender as a synonym for women, sexual difference, or sex roles, but it has now become a complex category of analysis. Joan Scott (2015) explains it as knowledge of sexual difference or the study of vexed relationships around sexuality (Scott, 2015). Teresa de Lauretis means by gender as 'the product and process of several social technologies' (cited in Wallace, 2009) due to which men and women consider themselves as gendered beings and not as human beings. It implies that gender is not a natural phenomenon but rather a cultural one, where it is socially constructed. The United Nations Entity for Gender Equality and the empowerment of Women considers gender as 'refers to both women and men, and the relations between them' (OSAGI, 2001).

Gender also 'refers to the social attributes and opportunities associated with being male and female and the relationships between women and men, girls and boys, as well as the relations between women and those between men. These attributes, opportunities, and relationships are socially constructed and are learned through socialization processes. Gender issues include all aspects and concerns related to women's and men's lives and the situation in society, to the way they interrelate, their differences in access to and use of resources, their activities, and how they react to changes, interventions, and policies'(Aguirre et al., 2014). This definition shows that the term gender goes beyond the identity of a person and considers gender as a system of inequality, embedded in culture and society. Thus, gender issues are all those problems and concerns which affect women's rights and give them a subordinate role in society while the men are privileged and hold an authoritative position in the society.

Fairclough (1989) is of the view that ideology is encoded in discourse and expressed through lexical, grammatical, and textual items. Any change in these items will reveal a different ideology and are considered as ideological manipulation (cited in Mansourabadi \& Karimnia, 2013). Thus, the current study considers ideology to be an important factor that may influence the translators in their selection of lexical choices while translating the gender issues from Urdu into English. The findings of the study will enlighten the translators on the degree of severity caused by/of lexical choices towards gender issues and ideology of the writer.

Discourse analysis is considered effective in the examination of underlying ideologies. Ideology can be used to manipulate a work of translation. Farahzad has distinguished two types of manipulation that is conscious and unconscious manipulation. Conscious manipulation arises due to ideological, economic, social, political, and cultural factors while unconscious manipulation arises due to human psychology, ignorance i.e., lack of language and world knowledge.

The present study aims to employ the CDA approach based on Farahzad's model (2012) to unearth the underlying ideological manipulation of gender issues. These manipulations are invisible in the target text for the translators have provided a comprehensive preface and 
introduction along with a short glossary of cultural and religious words but the changing phenomenon or ideological manipulation have not been explained nor their translation strategies have been discussed in the preface.

Farahzad's (2012) model of CDA has three analytical dimensions, i.e. Intertextuality, CDA, and Translation choices. The relation between the source and target texts are explained in terms of intertextuality. Farahzad's view is that the relation between the source and target texts is not based on equivalence, sameness, or the origin but rather on intertextuality. The idea of the interrelatedness of texts with each other was put forward in the 1930s in literary studies. Kristeva is of the view that a text is not an isolated piece but a replacement of text in which many utterances taken from other texts form part of other texts. She believes that any text is the absorption and transformation of the previous and form part of the chain of texts to come in the future (cited in Azadsarv et al., 2017).

CDA is the second dimension of the Translation Criticism model. CDA has widened its scope by encompassing various disciplines and topics in its envelope, such as identity politics, transition and social change, language policies, and the integration of macro-social theories with linguistic analysis, power, representation, identity issues, and ideology. These concerns are also related to translation studies and hence linked CDA with translation discipline (Farahzad, 2012). CDA thus critically examines the translations to reveal ideological manipulations and power relations. Dukate's (2007) typology of manipulation will form part of the CDA dimension of the model. This level will reveal the fact that what kind of manipulation occurred in the target text.

The third dimension of Farahzad's (2012) translation Criticism model is translational choices. It covers a vast area and has three levels which are textual, paratextual, and semiotic. The textual level is further subcategorized into the lexical and grammatical choice of the translator, overt and covert meaning and implications, etc. the paratextual aspect covers everything about the text, for instance, footnotes, notes, endnotes, preface, judgment, and comments. The socio-historical context of both texts is analyzed at this level. The last part of the translation choices dimension is of Semiotic which concerns with the graphic design of the book, illustrations, fonts, colors, etc.

Though the present study aims to base the analysis on Farahzad's model of CDA, it is necessary to limit its scope to intertextuality, CDA, and lexical aspect of the translation choices level. Moreover, the study is also limited only to the analysis of gender issues of both texts. The study has found a plethora of manipulation of gender issues; however, this study will take into account only a few examples due to space limitations. It has been found that the translators have positively represented the male characters of the novel while the protagonist and other women characters have been negatively portrayed.

\section{METHODOLOGY}

To achieve the objective of the study, this study has selected an Urdu novel Umrao Jan Ada written by Mirza Muhammad Hadi Ruswa (1899) and its translation into English as The Courtesan of Lucknow (Umrao Jan Ada) by Khushwant Singh and M. A. Husaini (2000) (Singh \& Hussaini, 2000).

Before comparing the source and target texts with each other, first, the source text was read to find the gender issues. After finding the related gender issues in the source text, they were noted and compared with their equivalent in the target text. Since the study adopted a CDA approach of Farahzad (2012) as a tool for data analysis, the contents of the aim critically examined both the 
micro and macro levels to find the ideologically loaded lexis. Numerous examples of ideological differences based on gender issues and their manipulation were visible in the target text.

As mentioned above, the Translation Criticism (2012) model is composed of three levels i.e., intertextuality, CDA, and translation choices. The intertextual elements related to gender issues will be compared with each other and ideological manipulation based on the typology of Dukate (2007) will be analyzed. This aspect will form the second level of the analytical model. The third level is the most exhaustive and vast measures are included in it to unearth the hidden ideology. In the textual category, the lexical items expressing the gender issues and having ideological connotations will be examined. The translation of such lexical items may be either the same, different, or tampered implications or sometimes even lost its ideological significance. Translators sometimes translate a non-ideological word into an ideologically significant word in translation.

The translators have presented a preface, short biography, short glossary of Urdu words, some historical personages, and translation of couplets at the paratextual level. The paratextual level will also be searched for the strategies of the translators while translating the gender issues. The paratextual level will only concern with the preface and glossary of Urdu terms coping with gender issues.

The last part of the CDA model is the semiotic level. It will take into account the book cover, color, and its design as compared to its original. After a careful comparison and examination, the analysis will reveal the underlying ideological structures found in the target text.

The focus of CDA is the analysis of discourse and language while taking into account the social and political issues to unearth the way; they affect each other. CDA considers language as a social activity that influences language users to employ a particular type of language. According to van Dijk (2004), Critical Discourse analysis is a type of analysis that primarily studies the way social power abuse, dominance, and inequality are enacted, reproduced, and resisted by text and talk in social and political contexts. It is concerned with the representation of social issues, hidden agendas, texts, and has an impact on the lives of the people (cited in Mengibar, 2015). CDA thus takes an ethical stance to address power imbalance, inequities, social justice agenda, and to urge readers to take resistive measures and corrective social action (Salma, 2015).

Many studies have focused on gender issues based on the CDA approach such as Toshtemir Alimove (2019) which investigates the impact of gender on the translation of the literary text. It aims to identify gender-specific language and the influence of the translator's gender identity at morphological, lexical, and syntactic levels. The study reveals the fact that grammatical gender creates difficulties for translators when they translate from source to target language (Alimov, 2019).

Klimovich (2018) has found Lawrence's novels Lady Chatterley's Lover, Sons and Lovers along with Dickens' Tess of the D'Urbervilles, where the translators have omitted many sexual scenes, and obscene words due to cultural norms. The religious links of the novels are also not easy to translate due to ideological influence. The findings of the study show that censorship and ideological difference generate manipulative strategies, the omission of the undesired elements, substitutions often either take the form of synonyms or antonyms. These manipulative changes occurred at semantic, pragmatic, and expressive levels (Klimovich, 2018). Rojas and others (2018) have analyzed the Spanish translation of Oscar Wilde's fairy tale The Happy Prince in terms of gender issues, the study is confined to the translation of grammatical gender and sexuality. The findings exhibit that the translator has omitted entirely the value of homosexual love to conform it to the traditional view of sexuality in the Western tradition. The analysis took place at the linguistic, stylistic, and cultural choices level of both texts (Rojas-lizana et al., 2018). 
The prior studies have focused on the manipulative aspect of gender and sexual issues at the grammatical level but so far as we know, none of the past studies have focused on the positive representation of the self (patriarchy) and negative representation of the other (women). This study is an attempt to unearth the ideological manipulation in the translation of gender issues in the Urdu novel Umrao Jan Ada translated into English as The Courtesan of Lucknow based on Farahzad's (2012) CDA model and Dukate's (2007) typology of manipulation.

\section{DUKATE'S TYPOLOGY OF MANIPULATION}

Manipulation is comparatively a recent phenomenon in translation criticism. It is proposed by the manipulation school and developed by Lefevere (1992). He believed that translation is a rewriting of the source text and is manipulated by ideology, poetics, patronage, and universe of discourse. Dukate (2007) views manipulation as 'the translator's / interpreter's handling of a text which results in the adaptation of the text for the Target Audience, considering the cultural, ideological, linguistic and literary differences between the cultures in contact, which takes place within a particular cultural setting and is carried out by a human agent, with the consequence of a possible influence of individual- or psychology-related factors upon the end product'(cited in Farahani \& Arbabi, 2016). There are two main types of manipulation i.e., text-external and text-internal manipulation. Both types of manipulation have further branched out into three types of manipulation which are (1) manipulation as improvement, (2) manipulation as handling, and (3) manipulation as distortion. These types of manipulation can be either conscious or unconscious. The types of manipulation is presented in Figure 1.

Figure 1.

Dukate's Typology of Manipulation

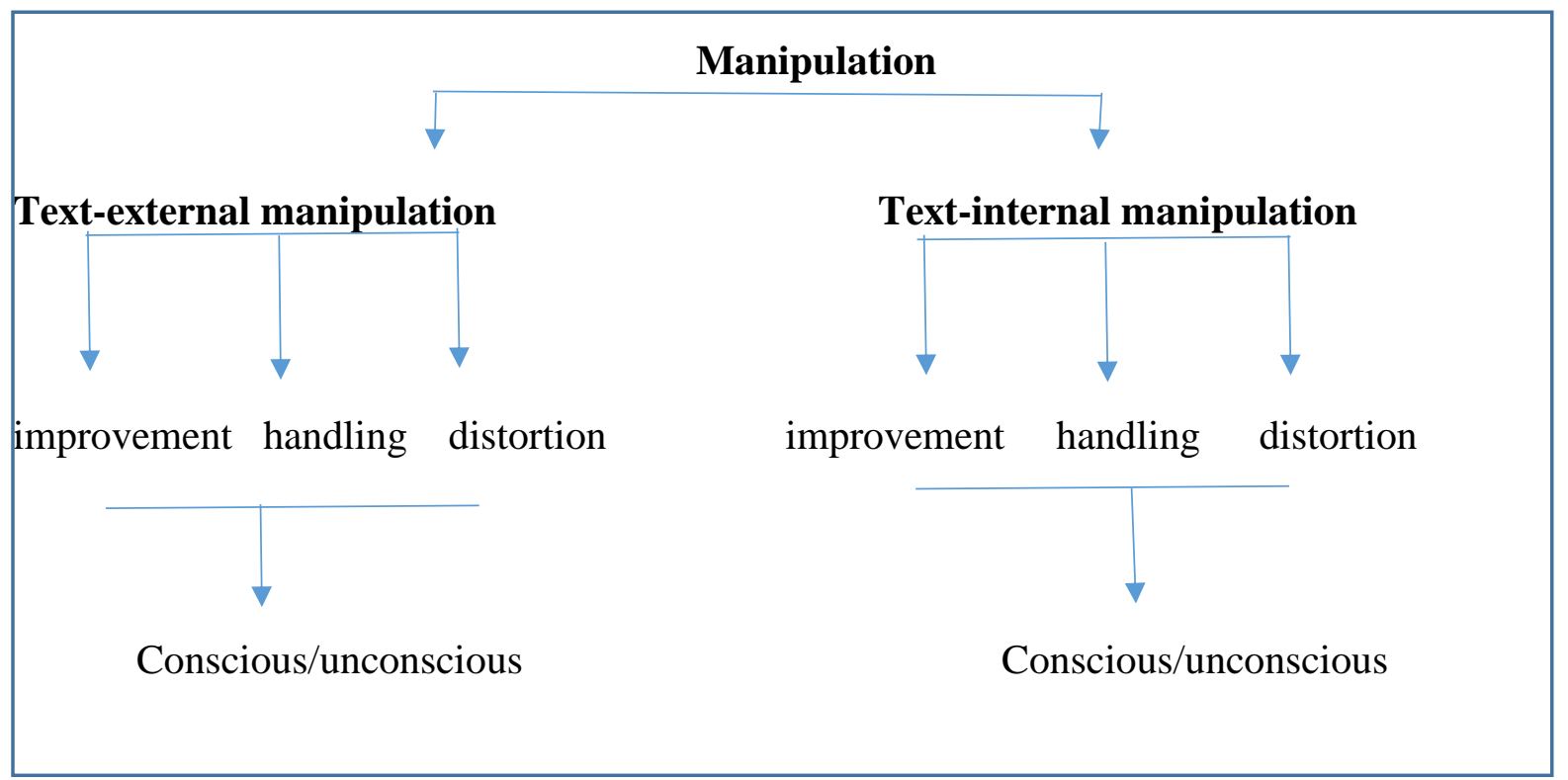


Text-internal manipulation occurs within the text including manipulation as handling, manipulation as change (distortion), and manipulation as an improvement. These manipulations can be either conscious or unconscious manipulation. While the external manipulation takes place outside the text. It can be explained in terms of polysystem theory i.e. the external struggle for power of texts, cultures, and literary systems. The various actors who can perform manipulation in external manipulation are the commissioner, the publisher, translator, editor, reviser, critic, etc.

Dukate (2007) further distinguishes between conscious and unconscious manipulation. Conscious manipulation is intentional manipulation and can be either ideological or linguocultural. There are various factors behind conscious manipulation such as ideological, economic, social, political, and cultural factors (Klimovich, 2015). While unconscious manipulation is unintentional and follows from the human psyche. It may show itself in translation as normalization, explicitation or digression or it can also result from ignorance and errors of various kinds (Dukate, 2007). The translator is then, considered responsible for the unconscious translation.

The present study seeks to investigate the ideological manipulation of gender issues based on the translation criticism model of Farahzad (2012) and Dukate's (2007) types of manipulation employed in the process of the translation of Urdu novel Umrao Jan Ada into English as The Courtesan of Lucknow. Dukate's (2007) typology of translation is also adopted for the analysis of the study. This part also presents the gender issues which have been manipulated in the target text after comparing them with their corresponding extracts. After extracting and comparing the data, the analysis of each gender issue is then provided immediately. In each analysis sufficient information is provided together with the type of manipulation. The literal translation of the source text in Italics has also been presented for non-Urdu readers. The following lines examine the three dimensions of the analytical model. The first one is intertextuality.

\section{INTERTEXTUALITY}

Intertextuality denotes the interconnectedness and interrelatedness of texts. The new text is considered as part of the past texts which influence one another. There are various cultural and religious references in the source text having a relation with gender issues. The translators' choice of the lexical items of intertextual elements has manipulated the ideology of the original. The following example will illustrate the point.

1. ...whose daughter's name had been coupled with a man's. (TT, p. 83 and 90) ... Whose daughter had been declared and chosen by force to be his wife. (Literal translation)

$$
\text { ان كى لزُكى ير كَالى جزٌ هـ جكى تهى. صفح 38، } 42
$$

The word كالى جرْ هنا declaration is made by force without the consent of both the family and the bride. It is a custom of the source culture when these words are spoken about a girl that she will be the wife of that person, whether she wishes him or not, then no one will marry her. The translators' choice of the word i.e. coupled is not a true substitute for this cultural word. The translators have thus omitted the cultural connotation as well as the response of the readers that the writer wants to highlight in the source text against this discriminatory element of the source culture. 
2. $\quad$ By Allah, you have a lovely hand! I am delighted. (TT, p. 71)

By God, it is a lovely handwriting, I am delighted that you are well educated. (Literal translation)

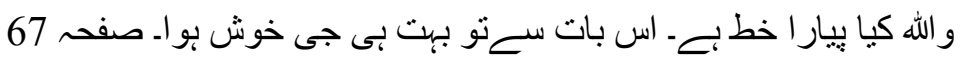

There is a conversation between Umrao Jan and Nawab Sultan. The Nawab sahib appreciated the literary mind, being educated, and handwriting of the protagonist. The writer has tried to highlight the benefits of education and its importance for women but the lexical selection of the translators has diverted the attention of the readers from education to the beauty of the body of the protagonist. The lexical choice of translators is such that Nawab appreciated the hand of Umrao Jan instead of her writing and education. The distortion type of manipulation occurred in the target text.

\section{TRANSLATION CHOICES}

As explained above this dimension of the analytical model will examine the textual, paratextual, and semiotic levels into consideration.

\section{The Title of the novel}

TEXTUAL LEVEL

The title of the source text is Umrao Jan Ada. It is the name of the protagonist of the novel. Her real name is Ameeran but after her abduction and being sold in the prostitution market, she is named Umrao sahib by Khanum Jan. After the performance of a cultural event of Missi (debut deflowering of the prostitute); the word Jan is added to the name of the prostitute to signify that the girl is now fit as a sex worker. Later on, the protagonist (Umrao Jan) added Ada as her pen named by herself. The translators have explained more the title of the novel i.e. The Courtesan of Lucknow (Umrao Jan Ada). The manipulation that takes place here is an instance of text-internal manipulation under Dukate's typology of manipulation. One of the most important themes of the novel has been laid bare to the readers. But besides being a courtesan, the protagonist also acted as a poetess, professional singer, and dancer. She is known far and wide for her poetry, singing, and dancing but the title has made hidden this aspect from the readers. It reveals to the readers that it will be the immoral ways of the life of a courtesan, for the artistic qualities of Umrao Jan have not been mentioned in the title unless the readers read it to the very last page. The translators have provided numerous instances of the negative presentation of the protagonist, it seems to be that gender bias is working in a secretive way. For they (translators) have presented the protagonist in various instances negatively while various males have been represented positively through their lexical choice. The title is one such example. The following example is also a similar example of the positive representation of the $U s$ (men).

4. It was here that I used to trade my honor for money, for this was the Chowk, the prostitutes' quarter. (p. 33, Singh \& Hussaini, 2000)

(it was the market where there was the shop of my honor selling, i.e. the Chowk (square) (Literal translation)

$$
\text { يـ وه باز ار تهاجهان ميرى عزت فروشى كى دكان تهى. صفح } 37
$$


The translators have depicted the narrator in a way where she on her own will trade her honor for money. But such is not the case in the source text because the writer (Hadi Ruswa) depicted the narrator (Umrao Jan) in a way where she was compelled and forced to do the work of prostitution. The writer wants to convey the sexual exploitation and abduction of little girls, poor and unemployed women. A contrastive ideology of prostitution has been presented in the target text due to its lexical difference from that of its original. The manipulation that has taken place here, manifests itself as the distortion typology of Dukate. The writer (Hadi Ruswa) shows the sexual exploitative nature of men in the red district where men come as customers to buy and rule over the body of the poor and economically dependent women. The women have no choice but to sell their bodies for sexual gratification, singing and dancing and poetry to men. But the translators have distorted and negatively presented that Umrao Jan on her own free will acted as a courtesan for money.

5. I was a woman with a woman's intuition and knew what was best for me. (TT, P. 38)

(but even then the woman folk is very intelligent/ingenious) (Literal translation)

$$
\text { مكر يهر بهى عورت زات برّى بوشيار بونى به - } 41 \text { صفح }
$$

The writer has tried to convey that woman are very intelligent in general but the translators have brought two changes in it. The first is the tense of the sentence is changed from present to past and second, the attribute of intelligence of woman is substituted with woman's intuition. The simple sentence is changed into a complex sentence along with the taming of the general attribute of intelligence to the woman. The translators seem to give no credit to the womenfolk in general and so the positive attribute is made silent in the target text. The distorted type of manipulation has taken place over its interpretation.

6. The school was under the supervision of a Maulvi Sahib. (TT, P. 41) Maulvi Sahib was a servant. (Literal translation)

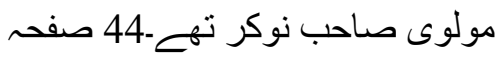

Khanum Jan was a brothel keeper. She employed many persons to educate her prostitutes in religious education, Persian language, and literature, poetry, dance, music, and coquetry. She was the owner of a religious school and employed Maulvi Sahib where her prostitutes were trained in Islamic religious education. Maulvi Sahib was her servant but the lexical choice of the translators in the translation of the above sentence showed that Maulvi Sahib was the owner and supervisor of the school. The economic independent nature of Khanum Jan, as well as her ownership, have been made hidden in translation. The institute of prostitution has employed many employees in it, such as Maulvi Sahib in religious school/seminary and poetry to teach Persian language and literature, Ustad Ji was employed to teach music, others were kept for security purposes, Hussaini performed the duties of a nanny, and coquetry, Gauhar Mirza as a pimp, etc. So, Maulvi Sahib was from the men folk as well as belonged to Islamic religion, but despite his association with prostitutes, the translators have presented a positive image of the Maulvi Sahib by concealing his employment under the supervision of chief courtesan Khanum Jan.

7. Gauhar Mirza was the son of Nawab Sultan Ali Khan, a wealthy nobleman and singing girl called Banno, with whom the Nawab had a liaison. (TT, p. 44) 
IJoLLT Vol. 4, No. 2 (September) 2021

eISSN: 2637-0484

(Nawab Sultan Ali Khan was an aristocrat, he had a liaison with Banno Domni. The child (Gauhar Mirza) was born to their liaison) (literal translation)

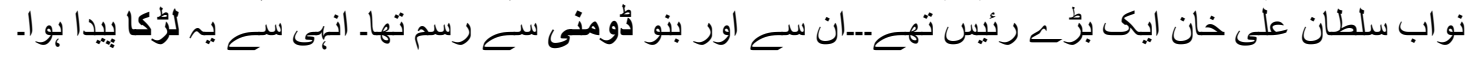

There are two translation problems in this sentence which have been made bold, the first is the word son and the second is the word, singing girl. Gauhar Mirza was the love child of Nawab Sultan Ali khan and Banno Domni. Domni is a cultural word and refers to a race whose profession is singing. The cultural reference is omitted in the target text and in its place a general word is substituted for it i.e., singing girl. The phrase singing girl does not allude to the race of the Banno. The race is generally poor, destitute, and earns their living often through prostitution also (Kalita, 2009; McNeil, 2009). Secondly, the writer used a general word i.e., child for their (Nawab and Banno) son because of having a liaison. A child born to such a liaison cannot be called a son but the translators used it instead. The writer used a general word for it but the translators used the word son for it, hence their lexical choice veiled the concept of a love child and the extramarital affairs of Nawab Sahib. The translators have thus manipulated and distorted the idea of the original and the presence of the sexual exploitation of women. Moreover, the status of the love child is also censored by the lexical choice of the translators. The manipulation that takes place is an instance of distortion according to Dukate's typology of manipulation. The writer (Hadi Ruswa) wants to convey the sexual exploitation of the wealthy men on poor women. The writer (Hadi Ruswa) has nobly highlighted the sexual exploitation and extramarital affairs of the elite and rich class but the translators have distorted and veiled sexual exploitation of the elite class of the poor. Hence, the distorted type of manipulation occurred in the interpretation and representation of the poor women in the TT.

8. I remember one event; the deflowering of Bismillah Jan. It was celebrated in great style.

The Missi of Bismillah Jan was celebrated with great pomp and show.

$$
\text { بسم الله كى مسى برّك دهوم سـح بوئى. صفح 51،51، }
$$

The word مسى (missi) is a cultural word and refers to a type of marriage like celebration among prostitutes. A person who pays for the celebration usually is entitled to lose the virginity of the prostitute during the performance and celebration of missi. It is an entry of a prostitute into the profession of prostitution. But the translators used the foreignization strategy and omitted this cultural word. The cultural word is substituted with a general word deflowering in its place; deflowering conveys the idea of the loss of virginity by force or against the wishes of the victim but the missi conveys the loss of virginity with the mutual accord of both parties; hence, the distortion manipulation takes place. The word 'deflowering' lacks the cultural reference as the word مسى (Missi) conveys. After the performance of this cultural event, the word Jan is added with the name of the prostitute to show that she has been deflowered and entered into the sex profession (Sachdeva Jha, 2009). It also shows that the prostitute has lost her virginity and now can act as a sex worker.

9. I believe in villages it is still customary to get girls to sing obscene songs.

The prostitutes of the village have to sing songs among men (Literal translation)

$$
\text { ديهات كى رنذيون كو كانا يُرنى بين مردون ميّ- صفح } 54
$$


The translators have changed the lexical items of the above sentence, the prominent are girls and obscene songs, these words have been made bold and underlined in the TT. First, they substituted the girls for prostitutes and songs for obscene songs. The writer has conveyed the point that both men and women are involved in prostitution. But the lexical choice of translators and the omission of the word men of the source text in the target text show their tendency not to spoil the patriarchy but such approach shows their gender bias in translation. The omission of the word among men signifies the point that the translators do not want to tarnish their name. The manipulation censored the ideology that men are also involved in immodesty of women as well as the sexual exploitation of women. The women are used for the entertainment purpose just to satisfy their lust. The translators have muted the criticism on men folks who are involved in the exploitation of women in their translation. The message and criticism of the writer has been distorted under Dukate's typology of manipulation.

10. Gauhar Mirza (who was the first one to pluck the flower) kept visiting me. (TT, p. 62)

Gauhar Mirza, the first deflowerer, kept a regular meeting every time. (Literal translation)

$$
\text { كل جين اول كو بر مرزا مجه سـح بر زمانه ميس بر ابر ملتا ربا. صفح } 60
$$

The literal meaning of the phrase كل جين اول means the person who plucks the first flower, here it is a metaphor and means the first person who deflowers the narrator (Umrao Jan) of the novel. But the translators render it literally and thus censor the intended meaning of the source text. The target text has implied the meaning of the sexual exploitation by man (Gauhar Mirza) of woman (Umrao Jan) before marriage. The distorted type of manipulation does not render to the readers the metaphoric meaning of the source text for it is an instance of the sexual exploitation of the women and dependence on men. The lexical choice of the translators and the literal translation of the metaphor have thus censored an important theme of the sexual exploitation of women.

11. At long last, I was on my own. Page 62

اب ميس كويا آز اد بو كئى. صفح 60 Now, as if I had got the liberty. (Literal translation)

The writer presented the idea that Khanum took the money from other people and rendered them the services of a prostitute. The prostitute in turn did not receive any money except the one offered in secret to them by the visiting persons. Khanum ruled on the body of the prostitutes for money and exploited them. The prostitutes did not enjoy any power over their bodies. The writer has tried to show the nature of sexual exploitation in prostitution. But the translators' choice of the lexis gives the idea that Umrao Jan had got the liberty and lived on her own. The writer used a conditional sentence in the source text. She is allowed by Khanum to exchange her body for money for the first time and this change in her life is considered as liberty in her life. But the translators use of at long last signify that she (Umrao Jan) has got liberty from Khanum but such is not the case. The translators have again tried to show to the readers the strong urge of Umrao Jan for carnal desires. Again, this is an instance of negative representation of the protagonist and the distortion manipulation under Dukate's typology. 
This aspect of the CDA model will take into account the preface and glossary of the target text and will show how the translators have planned to do their translation of gender issues.

Preface

The translators present a short biography of the writer that mainly focuses on his thought and his multi-dimensional personality before the preface. The preface is eleven pages long preface. It covers the information that how the writer met with the narrator of the novel. The translators also threw light on other works of the writer i.e. on Afshai Raz, Zat-i-Shareef, Shareef Zada, and Akhtakari Begum. They also gave detailed information about his life, interests, jobs, livelihood, his amorous temperament, and his love affair with a French lady (Mlle Sophia Augustine). Ruswa had series of successful marriages in his lifetime but his progeny is living in obscurity in India and Pakistan. A detailed picture of the writer is also portrayed in words by the translators. The detail is taken from the picture of the writer but it cannot be found in the target text. the rest of the preface i.e. from the second last para on page thirteen to page fifteen is about the novel Umrao Jan Ada. The first paragraph informs that the novel is a representative novel of Lucknow's socio-cultural, religious, and political history of the early twentieth century. The next para reports about the various important characters i.e., Gauhar Mirza, Rashid Ali, Faiz Ali, Akbar Ali Khan, and a seventy-year-old Nawab with whom the courtesan (Umrao Jan) had a liaison. One paragraph is also spared for Dilawar Khan who changed the entire life course of the protagonist. Ram Dei and Nawab Sultan are also mentioned in this para.

The concluding two paras are critical comments on the prose and poetry of the novel in particular and on the writer in general. The last two paras parted from the above paragraphs with a round bullet are considered to be the most important and relevant to the study. The translators here informed about the existence of a variety of editions of the source text but from the four texts, they chose the one that they 'considered the best' (Singh \& Hussaini, 2000). Besides they also 'take the liberty of deleting some passages, inserting new lines to link the sentences, and correcting a few minor details' (Singh \& Hussaini, 2000). Though the translators have informed about the deletion of passages and insertion of new lines and sentences but it has not been informed in the preface. This study has tried to find those passages and choices of lexis that have been changed from the gender perspective. The names of both translators are written at the end of the preface.

\section{Glossary}

A list of important cultural words (59 words) can also be seen at the end of the novel having the title of Glossary of Urdu words. These cultural words can be categorized into food items, dress, address words, religious words, and important religious, political, and literary persons, literary terms, musical terms, and finally literary allusions. Though it is a long list of various cultural words but still there are a large number of cultural words for which the foreignization strategy of translation could be a better option. But the translators have employed a Domestication strategy. There are also some words and phrases related to gender issues their translation into English have manipulated them, two of them have been explained above. There is also a separate list of the family of Nawab Wajid Ali Shah (the last ruler of Oudh 1847-1856, died in 1877), these include the mother, wife, son, and brother of the Nawab. A short bibliography is also after it. The bibliography is followed by the translation of most of the verses/couplets found in the source text. The communicative approach is followed in the translation of the verses of the novel. The 
IJoLLT Vol. 4, No. 2 (September) 2021

eISSN: 2637-0484

translators have also manipulated them but due to the limitations of the study, they have not been taken into account.

SEMIOTIC LEVEL

The semiotic aspect will examine and compare the cover, its color, and design of both original and target text. The aim is to highlight the difference and the meaning both convey to the readers in terms of gender issues.

\section{Front cover of source and target text}

The following is the comparison of pictures of the front covers of both source and target text. The source text has 786 on its top, which in Arabic abjad numeric refers to Bismillah-erRahman-er-Rahim (In the name of Allah the most beneficent and the most merciful). It signifies that the source text has a serious intention of absolving the society from the evils of sexual and economic exploitation of women at the hands of patriarchy. There is also a couplet written two times one above the title of the novel and one below it. The same couplet also explains the didactic and critical nature of the moral evils of the society. Thereafter, a short summary of the novel explaining the biography of an educated courtesan and the life and culture of Lucknow. It is followed by the name of the writer and publisher. The outline of the cover is enclosed in a framelike structure.

After comparing the front covers of the source text and target text, it shows the target text has omitted all the contents of the cover except the title, that too is changed into The Courtesan of Lucknow. The original title is enclosed with it in a bracket. There is also a short picture of a dancing pose of the feet of a dancing girl in the right-side corner of the book cover. There is also a pair of footwear jewelry with one foot in a moving or stepping direction. It signifies the girl to be a professional dancer rather than an ordinary girl. The picture of the dancing girl is up to the thighs. Besides the face of the girl is also made hidden on the cover to reveal the cultural ideology of purdah for women in general and the practice of dancing is also prohibited and not accepted in the Muslim culture. The background of the target text cover is blue with the yellow colour title of the novel. The flat surface seems to be the dancing floor for the dancing girl. The name of the publisher can be seen at the end.

\section{Figure 2}

Umrao Jan Ada front cover source text (Ruswa, 1922)

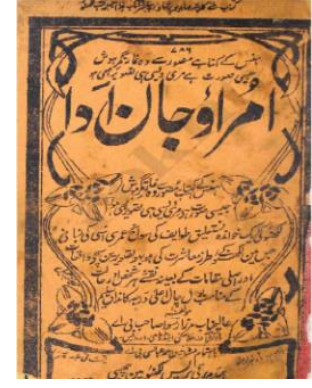

Figure 3 
IJoLLT Vol. 4, No. 2 (September) 2021

eISSN: 2637-0484

The Courtesan of Lucknow front cover target text (Singh \& Hussaini, 2000)

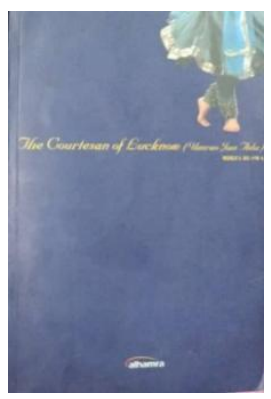

\section{Back cover of source and target text}

The following are pictures of the back covers of source and target texts. The back cover (fig 4) of the source text includes the list of the books of the author with the name of the bookseller.

The target text (fig 5) has two paragraphs and a couplet. The couplet is between the two paras. The first paragraph can be found on page 79 of the target text while the couplet is on page 80 of the target text. The first paragraph is taken from page 79 of the target text. It runs like this 'those evenings pass before my eyes when I think of them...smoke of the hookah' (Singh \& Hussaini, 2000). It is about her nostalgic feelings and yearning for her lover Nawab Sultan and the night concerts in his palace. The couplet below the first paragraph also presents the deep nostalgic feelings of the night performance. The translators have employed a communicative approach to the translation of the couplet. The first para is related to the romance and love affairs of the Umrao Jan Ada with a young Nawab (an aristocrat). It has hidden the didactic nature of the novel and especially the intense criticism on the sexual and economic exploitation of women by omitting the didactic couplet.

The second paragraph is about an introduction to the novel, the characters and their way of life, Lucknow's courtesans and their bedrooms, the life of an enforced prostitute, and culture at the time of Wajid Ali Shah. Both back and front covers have the same blue color. However, the researcher did not detect any significant ideological manipulation in the said para on back cover of the target text after comparing it with its original. Besides the two paras and a couplet, the target text has also the price, ISBN, QR code, and website of the publisher on the back cover.

Figure 4

Umrao Jan back cover ST

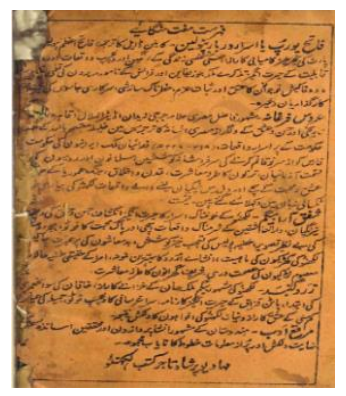

\section{Figure 5}




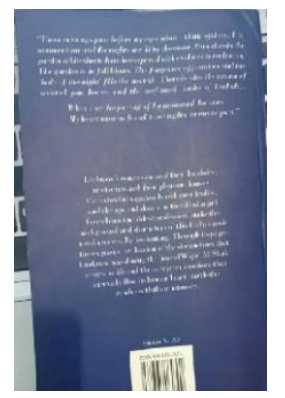

\section{DISCUSSION}

The analysis revealed that the lexical choices of translators have manipulated gender issues. The findings also revealed that the male characters have been positively represented while the women characters have been negatively represented. The target text has tried to adapt and bound it further to the ideology of the patriarchy. Both translators tried to follow the source text literally but the liberty in the lexical choice, omission, and communicative approach of translation of gender issues resulted in the manipulation of gender issues. The domestication strategy of some cultural words and ignoring the lexical choice of the source text have presented a different viewpoint to the readers. It seems that the lexical choices of translators are in line with the positive presentation of the self (men) and the negative presentation of the other (women).

Some passages have tried to strengthen the power relation of men over women while those passages have been either omitted or weakened when they are relevant to the economic and social independence of women. This ideological manipulation is due to the presence of superiority of men over women, established through culture. Flotow considers this as an instance of misrepresentation in patriarchal translation (Flotow, 2014). Venuti (2013) considers the different translations and different interpretations as an instance of bad translation when they desire to change at any price, impose cultural norms to master cognitively hence the singularity of the source text is denied in the target text (Venuti, 2013). The scholar further criticizes and terms this act of translators as an act of scandal who use translation in the service of the translating culture (Venuti, 1998). In consequence, this study extends the scope of translation in terms of ideological manipulation of gender issues and the positive representation of self and negative representation of the other in general and the translation of the novel Umrao Jan Ada in particular.

The study has found that the writer (Ruswa, 2000) has presented the trials and tribulations of the women, the lower status of women in the Indian society, the sexual objectification and exploitation of women, the gender roles associated with women and the forced inclusion of women into the sexual trade, in short the contemporary life and events, its language, poetry and music, the Nawabi culture and its cultural elements have been portrayed in the novel Omrao Jan Ada (Khan, 2019). Ruswa (2000) has also suggested that the women also suffered at the hands of men (Shah \& Zaidi, 2017).

But the translators have changed the themes related to the gender roles, they positively represented the male characters while negatively presented the women characters as the analysis shows in the above examples.

The positive presentation of the self and the negative presentation of the other can be made better shall the translators are made aware of the gender issues. This can be achieved by incorporating the themes related to gender issues in the pedagogy of translation study. 
IJoLLT Vol. 4, No. 2 (September) 2021

eISSN: 2637-0484

It is also suggested that before the publication of the target text it is recommended to ensure a comparative review of both texts in terms of manipulation and representation of gender issues in the target text.

\section{CONCLUSION}

The current study aims to explore the manipulation of gender issues in the target text while taking into account the translation criticism model of Farahzad (2012) and Dukate's typology of manipulation. The findings revealed the obvious distortion and manipulation of lexical items of gender issues. The analysis also illustrated that how the different lexical choices of translators altered the meaning of the source text of Umrao Jan Ada. The significance of the study can be expressed in a way that it has identified the approaches adopted by the translators in manipulating gender issues in their attempt to strengthen the patriarchal ways of life and bound the women to the whims of men.

The translators have negatively represented the women characters and whenever the women tried to break their traditional gender roles the translators have castigated them and expressed their disapproval in the target text. The writer Ruswa on the other hand, presented a noble cause of absolving the society from the social evils and the discriminatory attitude towards women in the patriarchal setup but the target text having a concealed patriarchal ideology has distorted the noble cause of the writer. Ruswa portrayed the women (prostitutes) as helpless and destitute creatures but the translators have victimized them in the above instances and many more instances in the target text.

Keeping in view of the translators' different ideologies, and their lexical choices from that of the writer's, it is hereby recommended for translators to take into consideration the gender issues of the ST during the process of translation. It is also suggested to professional and feminist translators to use the feminist strategies of Flotow (1991) to make the artistic work more feminist, move forward the manifesto of gender equality as devised through the goals of United Nations (2001) and OECD (2015) on gender equality.

Though the objectives of the study have been met, the present research has its limitations. This novel has also been translated by two other translators into the English language. It would be significant to study these translations also from a gender perspective to unearth the ways of manipulation. Since the study only investigated the manipulation of gender issues at the lexical level, it is called for future researchers to explore the study at syntactic and grammatical levels of Singh and Husaini's (2000) translation of Umrao Jan Ada. The results would also inform the possible manipulation at the mentioned levels.

\section{REFERENCES}

Aguirre, S., Borza, D. I., Burkevica, I., Humbert, D. A. L., Paats, M., \& Reingardè, D. J. (2014). Effectiveness of Institutional Mechanisms for the Advancement of Gender Equality Review of the implementation of the Beijing Platform for Action in the EU Member States. https://doi.org/10.2839/16888

Aklalouch, F. (2020). News Translation between Reality and Ideology towards a Critical Discourse Analysis Approach : Comparative Study between English News Reports by Reuters and their 
IJoLLT Vol. 4, No. 2 (September) 2021

eISSN: 2637-0484

Arabic Translations by Al-Jazeera MA in Translation Sciences \& Linguistics (Issue January) [Abdelmalek Essaadi University] https://www.mtslma.com/uploads/1/0/9/6/109689703/fatima_zahra_aklalouch_ma_thesis.p df

Alimov, T. (2019). Gender Based Problem in Translation of Literary Texts. Philology Matters, 2019 (3). https://doi.org/10.36078/987654367

Azadsarv, M., Heirati, J. K., \& Golzari, A. (2017). Critical Discourse Analysis of two Persian Translations of Lewis Carroll's Alices Adventures in Wonderland framed in Farahzad's CDA model. Research in Applied Linguistics, 8, 97-103. http://ttlt.azad.ac.ir/article_518717_690a6a50e03b4ee92a8e64765ee87897.pdf

Dukate, A. (2007). Translation, Manipulation, and Interpreting. Peter Lang.

Farahani, V. M., \& Arbabi, M. (2016). Manipulation in Drama translation: A case study of Waiting for Godot. International Journal of Research Studies in Language Learning, 5(4). https://doi.org/10.5861/ijrsll.2016.1316

Farahzad, F. (2012). Translation criticism: A three-dimensional model based on CDA. Iranian Translation Studies Journal, 9(36), 27-44.

Flotow, L. Von. (2014). Translation and Gender Translating in the "Era of Feminism." Routledge.

Hatim, B., \& Mason, I. (2005). The translator as communicator. In The Translator as Communicator. Routledge. https://doi.org/10.4324/9780203992722

House, J. (2018). TRANSLATION The Basics. Routledge.

Kalita, D. J. (2009). Zam-Zam, 5(1), 1-2.

Khan, M. wasif. (2019). The Other Woman Mirza Hadi Ruswa's Umrao Jan Ada and The Politics of Domesticity in Nineteenth century India. A Companion to World Literature, 1(11), 11. https://doi.org/10.1002/9781118635193.ctw10186

Klimovich, N. V. (2015). The Personality of Manipulator in Translation. Journal of Siberian Federal University, 12(8), 2861-2867. https://doi.org/10.17516/1997-1370-2015-8-12-28612867. Research

Klimovich, N. V. (2018). Translated Literature in the Russian Culture of the 20th Century: Manipulation and Censorship. 1(11), 98-105. https://doi.org/10.17516/1997-13700209.Research

Mansourabadi, F., \& Karimnia, A. (2013). The impact of ideology on lexical choices in literary translation: A case study of A Thousand Splendid Suns. Procedia - Social and Behavioral Sciences, 70, 777-786. https://doi.org/10.1016/j.sbspro.2013.01.123

McNeil, A. (2009). Tawa'if, military musicians and shi'a ideology in pre-rebellion lucknow. South Asia: Journal of South Asia Studies, 32(1), 46-62. https://doi.org/10.1080/00856400802709276

Mengibar, A. C. (2015). Critical discourse analysis in the study of representation, identity politics and power relations : a multi-method approach. Communication and Society, 28(2), 39-54. https://doi.org/10.15581/003.28.2.39-54

OECD. (2015). Gender equality and women's rights in the post-2015 agenda: A Foundation for Sustainable Development, 3(1), 1-16.

OSAGI. (2001). United Nations OSAGI Gender Mainstreaming - Concepts and definitions. https://www.un.org/womenwatch/osagi/conceptsandefinitions.htm

Rojas-lizana, S., Tolton, L., \& Hannah, E. (2018). “Kiss Me on the Lips, for I Love You " Over A Century of Heterosexism in the Spanish Translation of Oscar Wilde. International Journal of Comparative Literature \& Translation Studies, 6(2). 
IJoLLT Vol. 4, No. 2 (September) 2021

eISSN: 2637-0484

Ruswa, M. M. H. (1922). Umrao Jan Ada. Hamdam Barqi Press. https://www.rekhta.org/ebooks/umrao-jaan-ada-mirza-hadi-ruswa-ebooks-3

Sachdeva Jha, S. (2009). Eurasian women as Tawa'if singers and recording artists: Entertainment and identity-making in Colonial India. African and Asian Studies, 8(3), 268-287. https://doi.org/10.1163/156921009X458118

Salma, N. F. (2015). Exploring Van Dijk: Critical Discourse Analysis 's Aims. 1-9. https://doi.org/https://doi.org/10.17605/osf.io/mwrnq

Sanatifar, M. S. (2013). Translation , Manipulation and Social Movement. In American Journal of Translation Studies (Vol. 2).

Scott, J. W. (2015). Gender: Still a Useful Category of Analysis ? Diogenes, 7-14. https://doi.org/10.1177/0392192110369316

Shah, F. M., \& Zaidi, N. (2017). Ethos and ambience of 19 th century Lucknaw in the narration of Umrao Jan Ada. 1-11.

Sharififar, M., Bani, M., \& Azadi, A. (2016). Investigating Ideological Manipulation in Translation of Political Texts Case Study: Iranian Nuclear Talks. 3(2), 61-71.

Singh, K., \& Hussaini, M. A. (2000). The Courtesan of Lucknow (Umrao Jan Ada). Alhamra.

Somech, A., \& Zahavy, A. D. (2016). Gender Role Ideology. The Wiley Blackwell Encyclopedia of Gender and Sexuality Studies, 1-3. https://doi.org/10.1002/9781118663219.wbegss205

Venuti, L. (1998). The Scandals of Translation: Towards an Ethics of Translation. Routledge.

Venuti, L. (2013). Translation Changes Everything: Theory and Practice. In Translation Changes Everything. Routledge. https://doi.org/10.4324/9780203074428

Wallace, E. K. (2009). Encyclopedia of Feminist Literary Theory (E. K. Wallace (ed.). Routledge. 